\title{
Music-inspired free play to foster scientific exploration in early childhood
}

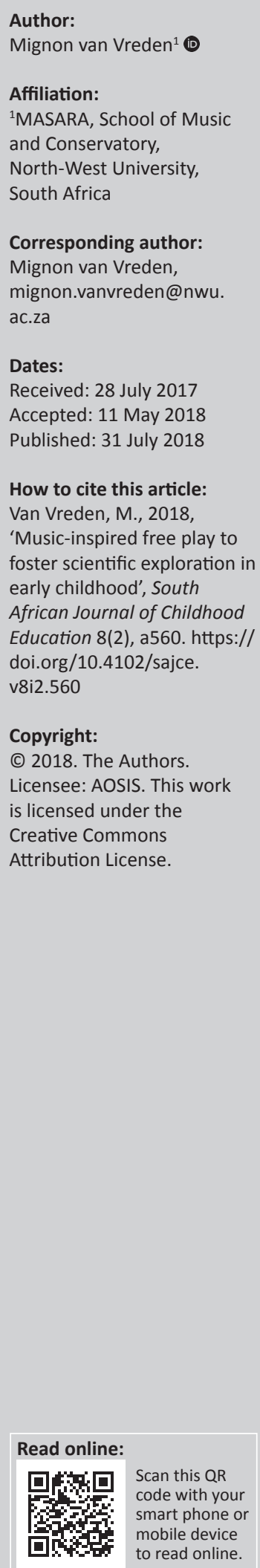

Background: The importance of music and play in early childhood development is widely acknowledged. However, no recent studies have investigated the potential of music-inspired free play to foster scientific exploration.

Aim: The purpose of this qualitative case study is to explain the rationale in utilising musical skills, knowledge and experiences during free play to foster scientific exploration, applying a constructivist approach with the learner placed at the centre of the educational process, while the teacher acts as observer and facilitator.

Setting: Data were primarily collected through documents to create a concept map that informed observations of preschoolers during free play at two day-care centres in Mohadin in the North-West Province of South Africa.

Methods: An explanatory case study provided the context for this study and a document analysis informed the findings.

Results: Through data analysis, key themes were identified from the literature and observations to generate a conceptual model that illustrates the influence of music-inspired free play to foster scientific exploration by stimulating creativity and emphasising the necessity of free play in preschool settings.

Conclusion: The conclusion of this investigation was a better understanding of the capacity of young learners to apply scientific exploration, utilising a transdisciplinary approach for teaching and learning the sciences in the early years to develop a better understanding of their world through music-inspired free play.

\section{Introduction}

In his keynote speech at the Early Childhood Development STEM Conference in Potchefstroom, former NASA deputy chief technologist Jim Adams emphasises the importance of including the arts in childhood education (Adams 2016). Sharapan (2012:36) supports the integration of the arts into learning during the early years not only to promote early childhood development, but also to assist educators to find creative ways to integrate scientific concepts into the curriculum, as artistic expression is a natural part of early childhood. STEM, an acronym for science, technology, engineering and mathematics, refers to science-related fields in education to reinforce the importance of scientific literacy in early childhood to promote scientific innovation (Sharapan 2012:36). With a proposed new addition to the acronym, $A$ for the arts, STEAM could integrate and use the arts in the STEM curriculum to help children express STEM concepts (Guyotte et al. 2015:1). Current efforts to promote STEAM education (STEM + arts) focus predominantly on how partnering with the arts provides various benefits to STEM learners, such as building a foundation of sciencerelated knowledge and encouraging children to express their ideas in various creative ways (Sharapan 2012:36).

In the South African Curriculum and Assessment Policy Statement (CAPS) (South Africa 2011) the subject Life Skills is aimed at guiding and preparing learners for life and its possibilities, and this entails equipping learners for meaningful and successful living in a rapidly changing and transforming society. Through Life Skills learners are exposed to a range of knowledge, skills and values that strengthen their physical, social, personal, emotional and cognitive development; develop creative and aesthetic skills; promote knowledge of personal health and safety; expand their understanding of the relationship between people and their environment; and enhance their awareness of social relationships, technological processes and elementary science. Early childhood educator and specialist Janse van Rensburg (2016) defines Life Skills as skills that learners are equipped with to survive in life and to express life. 
The visual representation in Figure 1 illustrates the study areas covered by the subject Life Skills, according to the South African CAPS (South Africa 2011), and how the skills and key concepts of each of these study areas are integrated in the foundation phase (Grades R-3). Science is a dimension of three components of 'Beginning Knowledge and Personal and Social Well-being', while music is a component of the study area 'Creative Arts'.

The aim of this explanatory case study was to explain the rationale for a constructivist, transdisciplinary approach to teaching and learning in the early years to foster scientific exploration through music-inspired free play. Wiggins (2009:23) describes constructivist education as a way of being rather than an approach, where the learner's own ideas are central to the learning and teaching process in which they are engaged. Shively (2015) defines constructivism as the way we make meaning of our experiences and come to know the world. For the purpose of this study I adapt Shively's definition as follows: how we make meaning of musical experiences and come to know the world through scientific exploration. I consequently investigated how the benchmarks of scientific literacy are related to music education through the analysis of documents and observations and explored the ways in which music is appropriate to inspire free play in the early years.

The main research question that guided this study was: 'What is the rationale for music-inspired free play to foster scientific exploration in early childhood?'

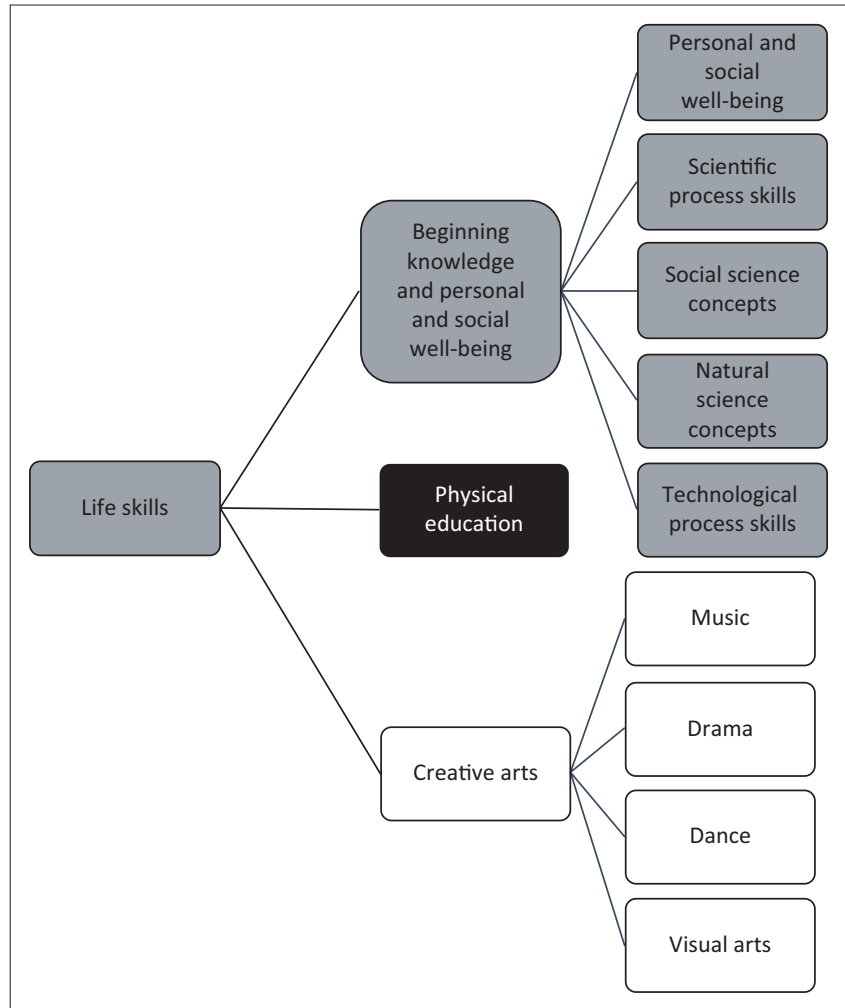

FIGURE 1: Life Skills in the Foundation phase.

\section{Background}

The inspiration for this investigation was an event that occurred during data collection for a multiple case study, which was exploring the teaching practices of early childhood teachers to ascertain how they integrate music with Home Language, Mathematics and Life Skills (van Vreden 2016). One morning I observed a 6-year-old boy who arranged a construction of colourful blocks of different sizes and called it a 'marimba'. This event occurred during free play the day after we had attended a musical play where preschoolers were exposed to a demonstration of various musical instruments, including marimbas. The 6-year-old's scientific exploration is an example of learning from music as part of a case study that produced a conceptual framework for music integration in Grade R (van Vreden 2014). The practical application of learning from music describes how a musical experience (in this case the tone colour of an instrument as well as the design and materials) could provoke thoughts and reflection during free play that inspire and stimulate a preschooler to apply musical knowledge to create something new through scientific exploration: a musical instrument replicating a xylophone. Scientific exploration was applied by experimenting with different lengths of building blocks to produce different tone colours and pitches. Tuned percussion instruments, such as a xylophone, consist of a set of wooden bars suspended on a frame. Hitting a bar makes it vibrate and produces a certain note, depending on the size of the bar. Longer bars produce lower notes, while shorter bars produce higher notes. This aspect of teaching and learning constructing a marimba from blocks during unstructured free play - illustrates how music inspired another activity that is different from the original activity, emphasising the value of learning through play. As demonstrated by this event, teaching and learning from music cannot always be predetermined by a specific teaching method or musical activity. Teaching and learning from music rather occurs spontaneously after learners have had ample opportunities for free play in order to explore in an informal way scientific concepts such as sound waves, dynamics (loud and soft), echoes, sound vibrations and sound production. Scientific exploration, in this case, was a response to teaching and learning related to music; stemming from an awareness of the way that learners spend their time during unstructured free play (Van der Linde 1999).

\section{Research methods and design Study design}

The study design of this investigation was a qualitative case study. Merriam and Tisdell (2016:37) define a case study as an in-depth description and analysis of a bounded system, while Yin (2014:16) describes it as an empirical inquiry that investigates a contemporary phenomenon within its real-life context, but the boundaries between phenomenon and context may not be clearly evident. Creswell's (2013) definition of case study research is:

a qualitative approach in which the investigator explores a bounded system (a case) or multiple bounded systems (cases) over time, through detailed, in-depth data collection involving 
multiple sources of information [in this study observations and documents], and reports a case description and case-based themes. (p. 97)

In this explanatory case study, data from observations and documents were analysed simultaneously with data collection. Merriam and Tisdell (2016:197) warn that data could be unfocused, repetitious and overwhelming without ongoing analysis because of the sheer volume of material that needs to be processed, but data that are analysed while being collected are both parsimonious and illuminating.

\section{Study population and sampling strategy}

The sampling strategy for the document analysis was theoretical sampling (Merriam \& Tisdell 2016:98), initially similar to purposeful sampling, based on the assumption that the research was intended to discover, understand and gain insight into a phenomenon, and therefore I had to select documents with the most learning potential (Merriam \& Tisdell 2016:96). Glaser and Strauss (1967:45) define theoretical sampling as the data collection process to generate a theory whereby a qualitative researcher simultaneously collects, codes and analyses the data and decides what data to collect next and where to find them, in order to develop an emerging theory. Collecting data for this study, I began with an initial sample (in this case documents related to the concept map) chosen for its obvious relevance to the research problem, namely to explain the rationale of music-inspired free play to foster scientific exploration. The collected data led me to the subsequent documents to be read. This was an evolving process guided by an emerging conceptual model of scientific exploration and music-inspired play, where analysis occurred simultaneously with identifying the sample and collecting the data. As data were being collected and theoretical constructs began to evolve, I also looked for exceptions to, or variants of, the emergent findings, as proposed by Merriam and Tisdell (2016:99).

The sampling criteria for the observations were that the preschools should be multicultural preschools situated in the community of Mohadin.

\section{Data collection}

Data collection for this explanatory case study was undertaken through document analysis, a complementary data collection procedure used in combination with nonparticipant observations to address the research problem. As a qualitative researcher, I drew upon multiple sources of evidence to seek convergence and corroboration through the use of different data sources and methods for triangulation (Bowen 2009:29). I used triangulation to assist me to guard against the accusation that this study's findings were simply an artefact of a single method, a single source or a single investigator's bias, as pointed out by Patton (1990). Merriam and Tisdell (2016:175) explain how data collection should be guided by questions, educated hunches and emerging findings. Although the search for relevant documents was systematic, I remained open to the accidental discovery of valuable data. I was consistent in tracking down leads, being open to new insights and sensitive to the data while observing participants and analysing documents (Merriam \& Tisdell 2016:175). There are many ways in which documents can be used in a case study to portray and enrich the context and contribute to an analysis of issues. Simons (2009) points out that even though formal document analysis tends to be used less than interviews and observation in case study research, its potential for adding depth to a case has not been fully exploited.

\section{Documents}

Documents are a ready-made source of data easily accessible to the imaginative and resourceful investigator (Merriam \& Tisdell 2016:162); they exist in both physical and online settings and include formal policy documents, public records and anything written or produced about the context of the case study (Simons 2009). Documents are a natural part of a research setting that do not intrude upon or alter the setting in the ways that the presence of the investigator might when conducting interviews or observations (Merriam \& Tisdell 2016:162). Using documentary material as data is not much different from using interviews or observations to uncover meaning, develop understanding and discover insights relevant to the research problem (Merriam \& Tisdell 2016:189). Unlike the case in interviewing and observation, the presence of the investigator does not alter what is being studied, because documentary data are objective sources of data compared to other forms. At the beginning of this study I considered what documents already existed that might be relevant to the case, using the stability of documentary material to my advantage. Merriam and Tisdell (2016:182) propose that the data found in documents can be used in the same way as data from interviews or observations to furnish descriptive information, verify emerging hypotheses, advance new categories and hypotheses, offer historical understanding, and track change and development.

\section{Observations}

Observation offers a first-hand account and allows for a holistic interpretation of the phenomenon being investigated (in this case, music-inspired free play to foster scientific exploration) when combined with document analysis (Merriam \& Tisdell 2016:161). It is the technique of choice when behaviour can be observed first-hand. Fieldwork for this case study involved visiting two daycare centres to observe preschoolers' free play inside and outside the classroom. The principals of the day-care centres granted me permission to observe the preschoolers during recess and as part of their daily programme in class to ascertain whether there are relations between music, free play and scientific exploration. I recorded my observations in as much detail as possible to form a database for analysis. My field notes included descriptions and my own comments, as suggested by Merriam and Tisdell (2016:161). 


\section{Data analysis}

The purpose of data analysis is to make sense out of the data through examination, consolidation, reduction and interpretation of what the researcher has seen and read through observations and in documents - the process of making meaning, gaining understanding and developing empirical knowledge (Corbin \& Strauss 2008; Merriam 1988:118; Merriam \& Tisdell 2016:202). Qualitative data analysis is inductive and comparative in the service of developing common themes, patterns or categories that cut across the data (Merriam \& Tisdell 2016:297).

During document analysis, documents are evaluated to produce empirical knowledge and to develop understanding (Bowen 2009:34).

This task involves skimming (superficial examination), reading (thorough examination), and interpretation. This iterative process combines elements of content analysis and thematic analysis. In this explanatory case study the process of document analysis consisted of three consecutive steps: (1) reviewing the literature; (2) applying creative reading; (3) producing a concept map for content and thematic analysis.

The literature related to this study was reviewed as a source of data, implying that I relied on the descriptions and interpretations of data rather than having the raw data as a basis for my own analysis. The analytic procedure entailed finding, selecting, appraising and synthesising data contained in the literature (Bowen 2009:28). The documents provided background and context, additional questions to be asked, supplementary data, a means of tracking change and development, and verification of findings from other data sources (Bowen 2009:30).

I applied creative reading for research, defined by Kara (2015:61) as careful, interpretive reading involving a fair amount of note taking. Data organisation and management were performed manually, assigning shorthand designations to various aspects of the data to easily retrieve specific pieces of the data. These designations were mostly words and short phrases. After assessing the authenticity and nature of the relevant documents, I adopted a system for manually coding and cataloguing them by establishing basic descriptive categories early on (Merriam \& Tisdell 2016:178) through concept mapping (Novak 1981), displaying major concepts from the literature and the connections between them (Kara 2015:61). Windsor (2013:276) describes concept mapping as a structured way of diagramming complex data to show the relationships between ideas in a way that is easy to understand. Hay and Kinchin (2008:171) remark that concept maps are often used in education, because mapping the same topic at different times is a good way of showing changes in understanding. For the purpose of this study, concept mapping was used to provide a visual map to structure the concepts, themes, categories and contents derived from content and thematic analysis.
Through content analysis, that is the process of organising information into categories related to the central questions of the research (Bowen 2009:32), data were then organised into major themes, categories and case examples (Labuschagne 2003). Krippendorff (2013:49) defines content analysis as an unobtrusive technique that allows researchers to analyse relatively unstructured data in the light of their meanings, symbolic qualities and expressive contents, as well as of the communicative roles they play. Through thematic analysis, which is a form of pattern recognition within the data, the emerging themes became the categories for analysis (Fereday \& Muir-Cochrane 2006). This step involved a careful, more focused re-reading and review of the data, whereupon I reviewed the selected data and performed coding and category construction, based on the characteristics of the data to uncover themes pertinent to the phenomenon (Bowen 2009:32).

\section{Ethical considerations}

As the observations involved human subjects, ethical approval was required by the Ethics Committee of the NorthWest University's Department of Research Support. Research was carried out with an ethical awareness that contributed to the credibility and reliability of the study.

\section{Findings}

The findings from the data analysis are structured as organised descriptive accounts (Merriam \& Tisdell 2016:202), themes and categories that cut across and explain the data as a concept map.

\section{Music-inspired free play}

Music is a form of interaction between children and the outside world; Robinson (2002) consequently proposes that movement and music could be used effectively to teach children, as they enjoy both. This assists children to learn about the world and themselves, as well as to broaden and deepen the possibility of orientation and successful action in diverse environments (Volchegorskaya \& Nogina 2014:367). Music in early childhood is one of the first natural and accessible 'tools' for children to express their thoughts, feelings and desires. Musical and artistic activities are especially important at an early age, nurturing the development of emotionality, imagination, creativity and gross motor skills.

Jeanneret and DeGraffenreid (2012:400) remark that preschool teachers gain knowledge about their learners through their daily interactions. This knowledge should be applied to create opportunities for teachers to observe unprompted and continuous play to capitalise on in teaching and learning. Not only is children's innate musicality expressed and developed when they are given the time to explore, it also creates freedom, flexibility and facilitation in the early years (Bond 2015:126) and gives rise to unexpected moments when 
learners integrate music into their own learning, especially through play, to explore their scientific world.

Early childhood is the time when children learn about their world primarily through the magical process of play. The substance of play in very young children is usually comprised of the environmental objects and experiences to which they have been exposed. If the music environment is sufficiently rich, there will be a continuous and ever-richer spiral of exposure to new musical elements, followed by a learner's playful experimentation with these elements (Levinowitz 1998:3).

In addition to encouraging children's musical play through enhancing behaviours and establishing an environment rich in accessible materials (the availability of musical instruments encourages play), the nature of children's music-inspired play could be further developed by early childhood educators who integrate music into their teaching by making musical knowledge, skills and experience part of the daily programme (Bond 2015:124). The acquisition of musical experiences can help to develop learners' musical skills (Cabedo-Mas 2013) and expand their musical knowledge. Music activities that contribute towards the development of musical skills, knowledge and experiences include, but are not limited to, musical notation and sight reading, listening activities, creating music and improvisation, instrumental play, body percussion, music and movement, singing and musical play. Children's innate musicality is expressed and developed when they are given the time to explore, empowered to make musical choices and provided with the support of adults who exhibit enhancing behaviours and pedagogical content knowledge (Bond, 2016:126). By using musical intonation patterns that activate musical abilities and encourage creative activity, learners could be motivated to create an instrumental accompaniment, to sing songs, to illustrate stories, poems and fairy tales, and to interpret musical and visual representations while playing (Volchegorskaya \& Nogina 2014:365).

Terry Wolkowicz, education director of the New Bedford Symphony Orchestra in Massachusetts, describes music integration as a mixed blessing, with the potential for developing in-depth understandings amidst concerns that it diminishes the integrity and authenticity of learning music (Wolkowicz 2017:40). Music integration has the potential to promote deeper understanding in other areas and increase retention and application of knowledge to future contents. Burnaford, April and Weiss (2001) see music integration as a way to look beneath the surface and expand the ways in which children learn and experience new ideas, as arts integration is concerned with intellectual work and with inquiry as a way to learn and grow. To encourage children to take something learned in one context and apply it in another, educators need to support transfer by structuring learning opportunities and activities that promote making connections (Perkins 1992:26).

\section{Scientific exploration through free play}

Children are intuitive scientists (Gopnik 2009), applying observation as the starting point for scientific thinking (Sylva, Roy \& Painter 1980). The term scientific literacy is widely used, but the definitions and conceptualisations vary. For the purpose of this research, scientific exploration will include, but not be limited to, scientific literacy and scientific thinking. Two of the most commonly used definitions of scientific literacy are the ones outlined in the Programme for International Student Assessment (PISA) 2006 scientific literacy framework and in the Benchmarks for Science Literacy of the American Association for the Advancement of Science (Laugksch 2000). Both frameworks imply that a basic understanding of scientific concepts and processes is relevant for everyone in their daily lives and lays the foundation for lifelong learning. Rather than focusing on memorised knowledge, scientific literacy reflects the ability to apply one's existing scientific knowledge in different everyday life contexts and situations (Hahn et al. 2013:113). According to the Pan-Canadian Science Framework (Canada1997), scientific literacy is an evolving combination of science-related attitudes, skills and knowledge. Learners need to develop methods of inquiry, as well as problem-solving and decision-making abilities, to become lifelong learners and to maintain a sense of wonder about the world around them.

Lind (1999) agrees that science is a process of finding out and for organising and reporting discoveries. Rather than being viewed as memorising facts, science is a way of thinking and trying to understand the world. Children's developing understanding of science begins in their everyday activities and conversations about the natural and technical world. Therefore Callanan and Jipson (2001:21) believe that socialisation may play an important role in the development of scientific thinking, depending on experience and cultural background. Miller (1983) postulates that scientific literacy in a contemporary situation consists of three dimensions: (1) an understanding of the norms and methods (the nature) of science; (2) an understanding of key scientific terms and concepts (science content knowledge); and (3) an awareness and understanding of the impact of science and technology on society.

In a culture increasingly pervaded by science, mathematics and technology, science literacy requires understandings and habits of mind that enable citizens to grasp what those enterprises are up to; to make some sense of how the natural and designed worlds work; to think critically and independently; to recognise and weigh alternative explanations of events and design trade-offs; and to deal sensibly with problems that involve evidence, numbers, patterns, logical arguments and uncertainties (AAAS 1993:XI). Although goals for knowing and doing can be described separately, they should be learned in combination in many different contexts so that they can be used together in life outside of school. According to Benchmarks for Science Literacy (AAAS 1993:XII), the common core of learning in science, mathematics and technology should be science 
literacy, not a separate understanding of each of the discrete disciplines. Moreover, the core studies should include connections between science, mathematics and technology as well as between those areas and the arts (including music) and humanities and the vocational subjects (AAAS 1993:XII).

Wilson (2007) differentiates between scientific thinking and the learning of scientific facts in that scientific thinking involves children in the process of finding out, leading them to make their own discoveries. To foster scientific thinking, teachers should view young children as active learners (rather than simply as recipients of knowledge) and give them varied opportunities to explore and experiment. These opportunities will allow children to construct meaning and develop understandings that are not only valid but also valuable in their ongoing intellectual development. Teachers should take advantage of the different ways science can be naturally integrated into a play-centred curriculum. 'Sciencing' occurs, in many cases, in what children already do and how they think about what they do (Wilson 2007). Children acquire fundamental concepts through active involvement with their environment. As they explore their surroundings, they actively construct their own knowledge. Because of variations in learning styles among groups of children and among different cultural groups, science content should be introduced when it is appropriate to do so.

In his poem 'The Hundred Languages of Children' (Gandini 2012), Malaguzzi states that what children learn does not follow as an automatic result from what is taught, but rather it is in large part a result of children's own doing, a consequence of their activities and an application of their resources (Biermeier 2015:72). Malaguzzi's philosophy is a blend of theory and practice that challenges educators to see children as competent and capable learners (Fraser \& Gestwicki 2002).

Some people view science as learning facts about the world around us, while others consider science and other ways of knowing as 'the having of wonderful ideas' (Duckworth 1987). Wilson (2007) indicates that this latter view of science and ways of knowing matches the characteristics of young children as learners. Shortland (1988:310) describes science as 'this century's cathedral building ... [and] this century's art' and claims that science is as central to a truly cultivated mind as literature, music and the performing arts. Young children are naturally curious and passionate about learning (Raffini 1993). In their pursuit of knowledge, they're prone to engage in poking, pulling, tasting, pounding, shaking and experimenting. From birth children want to learn and they naturally seek out problems to solve (Lind 1999:79). These actions and attitudes indicate that young children engage in scientific thinking and actions long before they enter a classroom (Zeece 1999). However, the question remains how young children develop an understanding of science, how this understanding can be promoted and whether the basic scientific knowledge that is later imparted in school can provide a basis for lifelong learning (Hahn et al. 2013).
To understand, promote and impart basic scientific literacy, creating opportunities for observations and actions through play could stimulate emerging scientific thinking.

The starting point for the learning of science and engineering at this early age is play (Tunnicliffe 2015:4). Whitbread et al. (2012) point out that play is the work of children and essential for intellectual achievement and emotional well-being. Learning through experience is developed in both spontaneous and directed play and introducing inquirybased science fits well into extended play activities progressing to challenges to solve, as play often only consists of problem-solving (Moyles 1989). According to the South African CAPS, the time allocated in the foundation phase to Physical Education and Creative Arts can also be used for free play time, as the physical skills learned and practised during free play can support the learning in these two study areas (South Africa 2011:11). Maths and science concepts and skills can be acquired as children engage in traditional early childhood free play activities such as playing with blocks, water, sand and manipulative materials, as well as during dramatic play, cooking and outdoor activities (Lind 1999). Providing young children with opportunities to recognise the presence of maths and science in their everyday activities helps them to build the basic understandings and interest for future learning and scientific thinking.

Studies on literacy and free play among preschool and kindergarten children in dramatic play settings indicate that play is an important matrix for developing literacy skills (Isenberg \& Jacob 1983). Vygotsky (1966) theorises that play assists young children to assimilate new information and to learn to use representational thought. When learning occurs voluntarily and purposefully during free play, the consequences of failure are reduced and less frustration is felt. However, according to Pickett (1998:230), play alone will not necessarily promote the desired learning, as when the teacher is involved. Teacher involvement does not mean that the teacher directs play but that he or she should observe children and create appropriate environments in order to extend knowledge and model skills and strategies. Biermeier (2015:72) points out that learning becomes individualised when it is the product of a child's guided construction rather than simply a teacher's transmission and a learner's absorption. She proposes that, to teach well, educators must ensure that creativity and innovation are always present. Although good teaching requires organisation and routines, it is never inflexible and rarely routine, as it 'dances with surprise, pursues wonder and finds joy at every turn' (Biermeier 2015:72). In my opinion, teachers should not be interfering with or facilitating free play but should present opportunities for free play and exploration and equip the learners with musical experiences, musical knowledge and musical skills to utilise during free play. Tunnicliffe (2015:6) explains that learners have to acquire the skills needed to carry out investigations before they can focus on inquiry alone. Therefore these learners often need some play to find out how things work as part of their development. Play has 
the potential to foster learning well beyond the preschool years, and therefore children of any age can benefit from increased opportunities to expand literacy during play, in appropriate environments, while engaging in supportive interactions with adults (Pickett 1998:230).

Preschoolers' casual conversations during free play exhibit curiosity and interest in making connections among things they experience in everyday life (Callanan \& Jipson 2001:27). Asking questions that provide evidence of scientific exploration in several ways includes asking for causes of events, noticing patterns and seeking definitions for new words (Callanan \& Jipson 2001:29). Charlesworth and Lind (1995) characterise specific learning experiences with young children as naturalistic (or spontaneous), informal or structured. These experiences differ in terms of who controls the activity: the adult or the child. Naturalistic experiences are those in which the child controls choice and action; in informal experiences the child chooses the activity and action, but adults intervene at some point; and in structured experiences the adult chooses the experience for the child and gives some direction to the child's action. According to the literature from this data analysis, naturalistic experiences are closely related to learning from music during free play, as these experiences are initiated spontaneously by children as they go about their daily activities. Lind (1999) suggests that with naturalistic experiences a teacher's role should be to provide an interesting and rich environment for the learner, observe the learner's activity, note how it is progressing and then respond with a glance, a nod, a smile or a word of praise to encourage the learner. Children need to know when they are doing the appropriate things. Early childhood teachers could utilise free exploring in the learning environment and be flexible, encouraging the learners to use their existing knowledge, skills and experience in solving problems and meeting challenges (Tunnicliffe 2015:9).

\section{A constructivist approach}

Music is an art form, but it also has measurable scientific dimensions, such as pitch (high or low), tempo (fast or slow) and volume (loud or soft). Young children could explore science and music through pitch, tempo, beat and dynamics and could learn how these blend to create music (Arbor 2017). The integration of music and science is embodied in the music of the spheres, the ancient concept that the universe is ordered in a manner consistent with principles of musical harmony. This idea has a long history, from the teachings of Pythagoras (са. 600 вс) through to Isaac Newton in the 18th century, who saw music and science as profoundly linked and inseparable and viewed the world with a sense of its unity that has been lost in our age of specialisation (Rogers 2016:41).

According to Callanan and Jipson (2001:42), developmentally appropriate science instruction should capitalise on young children's natural curiosity - rather than focusing on correct answers - where teachers engage learners in the process of doing science. This approach to education is based on the understanding that knowledge is constructed by children rather than being given or transmitted to them. In a constructivist approach, children are viewed as 'intellectual explorers' (Lind 1999) and 'theory builders' (Chaille \& Britain 2003). This approach assumes that, as they interact with the world around them, young children develop their own complex and varying theories about this world. Teachers working with a constructivist approach provide a supportive environment where young children are encouraged to test and revise their original theories. When applying the conceptual model for music-inspired free play to foster scientific exploration in the early years (Figure 3 ) in terms of this constructivist approach, the key ingredients for a supportive environment include the following: (1) a variety of interesting materials for children to explore and manipulate (musical skills, knowledge and experiences); (2) unstructured time for children to develop and test their own ideas (musicinspired free play); and (3) a social climate that conveys to the children that questions and experimentation are as valuable as knowing the right answers (scientific exploration). The constructivist approach places the child at the centre of the educational process, where the teacher's role is to serve as observer and facilitator rather than instructor (Chaille \& Britain 2003).

\section{Discussion}

During data analysis the initial concept map (Figure 2) developed into a model that illustrates the rationale for music-inspired play to foster scientific exploration (Figure 3). Starting from the centre of the model, facilitation of and exposure to musical skills, experiences and knowledge takes place. Learners are then able to use these musical skills, activities and skills in their free play, which could in turn foster scientific exploration.

Zentner and Eerola (2010) suggest that preschoolers have an innate capability not only to see patterns in science-related experiences but also to hear them in music. According to Phillips-Silver and Trainor (2005), an emphasis on learning through play and other everyday experiences in the early years is the most developmentally appropriate way to promote the learning of important mathematical concepts such as patterning. In the overall story of motion, vibrations

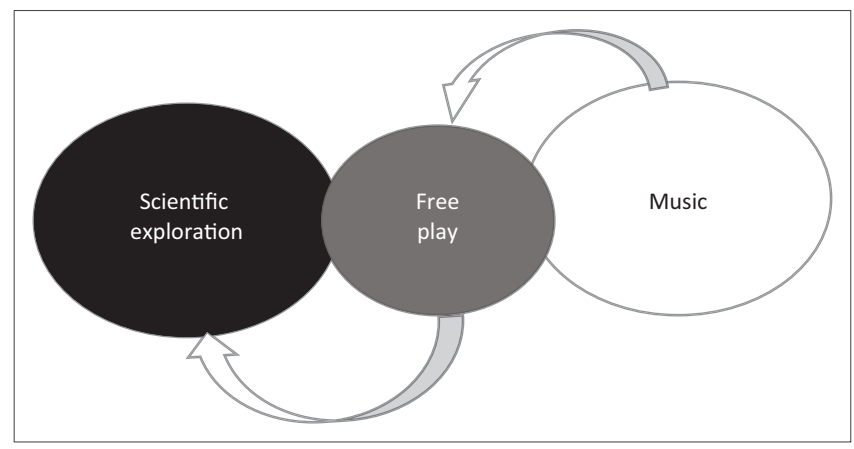

FIGURE 2: Concept map of music-inspired free play to foster scientific exploration. 


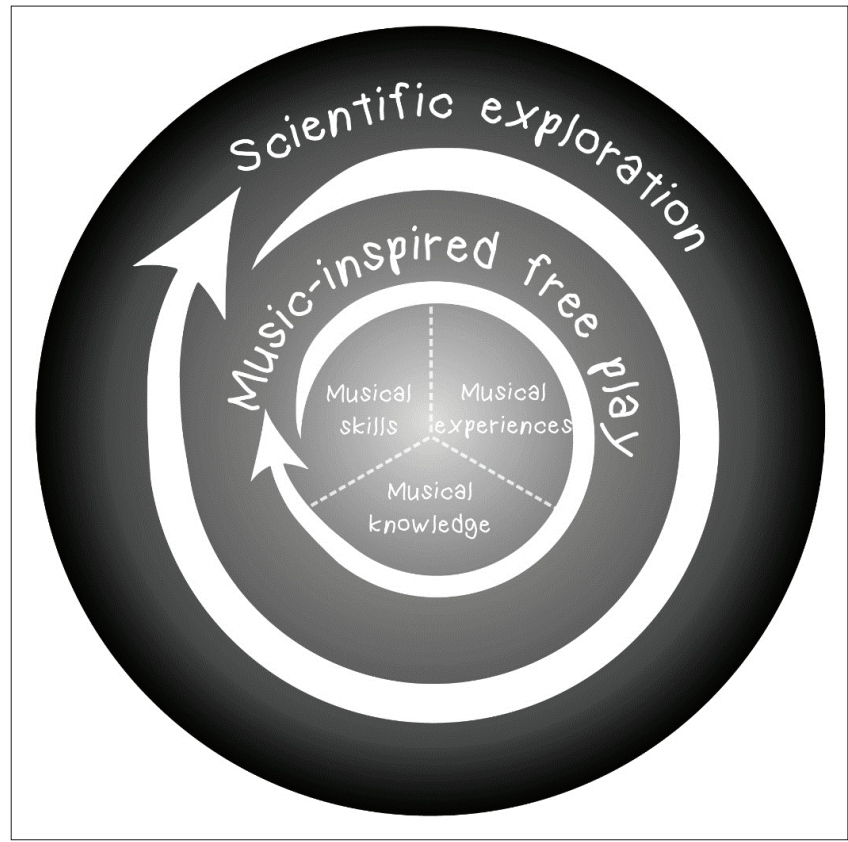

FIGURE 3: A conceptual model for music-inspired free play to foster scientific exploration in the early years.

serve in good measure to introduce the ideas of frequency and amplitude. Because there are so many examples of vibrating systems that learners can experience directly, they easily see vibration as a common way for some things to move and see frequency as a measure of that motion (AAAS 1993:88). In music, learners could explore whether a guitar string moves quickly (back and forth 1000 times a second) or slowly (only 15 miles or so per hour). To improve scientific literacy, one could investigate whether the Earth's rotation is slow (once a day) or fast (1000 miles per hour at the equator). Presumably, learners will start 'making music' from the first day in school, and this provides an opportunity to introduce vibrations as a phenomenon rather than a theory. With the drums, bells, stringed and other instruments they use, including their own voices, they would be able to feel the vibrations on the instruments as they hear the sounds.

Unique sounds and music could be created by using glasses filled with water. Learners would be able to distinguish between high and low, related to the musical concept pitch, by filling and emptying the glasses to different levels and in this way scientifically altering the pitch.

As my primary source of data was documents, the observations at two preschools in Mohadin only supplemented the primary data as practical examples to substantiate the rationale for music-inspired free play to foster scientific exploration. The aim of my observations was to identify and explore practical examples of musicscience relationships during free play. Because of time constraints, I was able to visit each preschool only twice, but in the activities that I observed the relationship between music and scientific exploration during free play was clear.
Preschool A consisted of four classes - one each for the 3-yearolds, 4-year-olds, 5-year-olds and 6-year olds (Grade R). This preschool has a large playground with a lot of play equipment. The different age groups take turns to play outside during recess for $45 \mathrm{~min}$ at a time. The principal informed me that the teachers do not teach music as part of the daily programme but that the preschoolers get the opportunity to sing and dance during outdoor play, as children enjoy music because it makes them happy.

Seventy preschoolers attend preschool B, a colourful school divided into three classes, for 4-year-olds, 5-year-olds and 6-year-olds (Grade R). A constraint at this preschool is a lack of space. Approximately 40 Grade $\mathrm{R}$ learners are taught in a small room of $5 \times 10 \mathrm{~m}^{2}$, formerly used as a single garage. During the daily programme the three classes take turns to sit and wait outside this classroom for their turn to go inside. The space outside is very limited and preschoolers do not have many opportunities for free play while they wait for their formal learning opportunities. They do, however, participate enthusiastically in singing, movement, body percussion and rhymes as part of their daily programme despite the lack of space.

At school A, a few children were rhythmically moving on the swings while singing the song 'Ring o' Rosies':
Ring-a-ring o' roses,
A pocket full of posies,
A-tishoo! A-tishoo!
We all fall down.

A scientific concept that is explored through free play on a swing is momentum. Stewart (2009) explains how the momentum a learner builds by moving his or her legs makes the swing go faster, while the swing will lose momentum when the learner's legs are no longer in motion and slow down until it stops. I observed how the swing gained momentum when 'Ring o' Rosies' was sung at a faster tempo to match the speed of the learners' movements. As soon as the learners slowed down, sang the song at a slower tempo and stopped moving their legs, the swing also slowed down until it eventually stopped.

At both preschools the preschoolers produced a variety of spontaneous musical sounds, phrases and chants to accompany their play. To foster scientific exploration based on these musical sounds, preschoolers could be made aware of sound production by using their voices and vocal chords, which vibrate to produce different sounds (Dixon \& Smith 1998:18).

Free play occurred not only outside the classroom during recess but also at different times during class, for example when a few girls in preschool A were tapping rhythms with their pencils on their desks while waiting for time to pass as their teacher handed out their books. According to Matacic (2016), scientists have shown that people without any musical 
training create songs using predictable musical beats, suggesting that humans are hardwired to respond to - and produce - certain features associated with music.

While observing the preschoolers outside at preschool A, a few of them spontaneously made remarks about sound production and described how they experienced this scientific concept through music-inspired role-play, pretending to be other people or famous actors. An outspoken boy informed me that his tonsils had been removed and that this operation influenced what his voice sounded like when he copied other people's singing. He explained that before the tonsillectomy, his tone of voice was much higher. Afterwards he found it easier to copy people with lower voices with a raspy tone. Another boy explained his understanding of sound production on a ukulele and how one has to turn the pegs in order for the sound to change, influencing the vibrations of the strings depending on the thickness of each string.

\section{Strengths and limitations}

This study was limited by a small sample size, the lack of generalisability associated with qualitative research, a limited time frame and seasonality. Despite these limitations, a model for further research to explain the rationale for music-inspired free play to foster scientific exploration in the early years was generated through the analysis of the data.

\section{Implications or recommendations}

By exploring the social contexts within which preschool children engage with scientific ideas, Callanan and Jipson (2001:45) propose that we may be able to learn more about ways that this process of discovery can be extended and encouraged through a constructivist educational approach (Wiggins 2009). Investigating whether and how these conversations vary across cultures, for example by incorporating indigenous knowledge, will be significant for future research.

\section{Conclusion}

Through this case study explaining the rationale of musicinspired free play to foster scientific exploration in early childhood, a model was generated from the data analysis. This model was based on an event that led to scientific exploration (constructing a musical instrument from blocks) and illustrates how an early childhood educator facilitated musical knowledge by exposing a preschooler to a musical experience (attending a musical play for preschoolers) that the preschooler subsequently integrated into his free play to foster scientific exploration. I propose that the occurrence of such an event in a natural early childhood setting could be the basis for encouraging early childhood educators to adopt the position of observers and facilitators, creating opportunities for constructivist learning to take place through reflection and exploration in free play.

\section{Acknowledgements}

This publication has been developed through the Teaching and Learning Development Capacity Improvement Programme which is being implemented through a partnership between the Department of Higher Education and Training and the European Union.

\section{Competing interests}

The author declares that she has no financial or personal relationships which may have inappropriately influenced her in writing this article.

\section{References}

AAAS - American Association for the Advancement of Science, 1993, Benchmarks for science literacy: Project 2061, Oxford University Press, New York.

Adams, J., 2016, 'Diamonds in the sky: Harnessing astronomy and spaces sciences for development', keynote paper presented at the early childhood development STEM conference, Potchefstroom, South Africa, 10th October.

Arbor, A., 2017, Preschool lab: Music and movement (ages 3-5), viewed 19 June 2017, from https://www.aahom.org/experience/programs/preschool-lab-music-andmovement-ages-3-5.

Biermeier, M.A., 2015, 'Inspired by Reggio Emilia: Emergent curriculum in relationshipdriven learning environments', Young Children 70(5), 72-73.

Bond, V.L., 2015, 'Created in context: A comparative case study of the use of music in two Reggio Emilia-inspired schools', Early Childhood Education Journal 43(2015), 119-126. https://doi.org/10.1007/s10643-014-0639-4

Bowen, G.A., 2009, 'Document analysis as a qualitative research method', Qualitative Research Journal 9(2), 27-40. https://doi.org/10.3316/QRJ0902027

Burnaford, G., April, A. \& Weiss, C., 2001, Renaissance in the classroom: Arts integration and meaningful learning, Lawrence Erlbaum Associates, Mahwah, NJ.

Cabedo-Mas, A., 2013, 'Positive musical experiences in education: Music as a social praxis', Music Education Research 15(4), 435-470. https://doi.org/10.1080/14613 808.2013.763780

Callanan, M.A. \& Jipson, J.L., 2001, 'Explanatory conversations and young children's developing scientific literacy', in K. Crowley, C.D. Schunn \& T. Okada (eds.) Designing for science: Implications from everyday classroom and professional science, pp. 21-49, Lawrence Erlbaum Associates, Mahwah, NJ.

Canada, Council of Ministers of Education, 1997, Common framework of science learning outcomes, $K$ to 12: Pan-Canadian Protocol for Collaboration on School Curriculum for use by curriculum developers, Alberta, Council of Ministers of Education, Toronto, ON, Canada.

Chaille, C. \& Britain, L., 2003, The young child as scientist, Allyn \& Bacon, Boston, MA.

Charlesworth, R. \& Lind, K., 1995, Math and science for young children, 2nd edn., Delmar, Albany, NY.

Corbin, J. \& Strauss, A., 2008, Basics of qualitative research: Techniques and procedures for developing grounded theory, 3rd edn., Sage, Thousand Oaks, CA.

Creswell, J.W., 2013, Qualitative inquiry \& research design, 3rd edn., Sage, Thousand Oaks, CA.

Dixon, M. \& Smith, K., 1998, Young scientists investigate sound and music, Evans Brothers, London.

Duckworth, E., 1987, 'The having of wonderful ideas' and other essays on teaching and learning, Teachers College Press, New York.

Fereday, J. \& Muir-Cochrane, E., 2006, 'Demonstrating rigor using thematic analysis: A hybrid approach of inductive and deductive coding and theme development', International Journal of Qualitative Methods 5(1), 80-92. https://doi. org/10.1177/160940690600500107

Fraser, S. \& Gestwicki, C., 2002, Authentic childhood: Exploring Reggio Emilia in the classroom, Delmar/Thomson Learning, Albany, NY.

Gandini, L., 2012, 'History, ideas, and basic principles: An interview with Loris Malaguzzi', in C.P. Edwards, L. Gandini \& G.E. Forman (eds.), The hundred languages of children: The Reggio Emilia experience in transformation, 3rd edn. pp. 27-71, ABC-CLIO, Santa Barbara, CA.

Glaser, B.G. \& Strauss, A., 1967, The discovery of grounded theory: Strategies for qualitative research, Aldine, Chicago, IL.

Gopnik, A., 2009, The philosophical baby: What children's minds tell us about truth, love, and the meaning of life, Farrar, Stralis \& Giroux, New York.

Guyotte, K.W., Sochacka, N.W., Costantino, T.E., Kellam, N.N. \& Walther, J., 2015, 'Collaborative creativity in STEAM: Narratives of art education students' experiences in transdisciplinary spaces', International Journal of Education \& the Arts 16(15), 1-38.

Hahn, I., Schöps, K., Rönnebeck, S., Martensen, M., Hansen, S., Sass, S., et al., 2013 , 'Assessing scientific literacy over the lifespan - A description of the NEPS science framework and the test development', Journal for Educational Research Online 5(2), 110-138. 
Hay, D. \& Kinchin, I., 2008, 'Using concept mapping to measure learning quality', Education and Training 50(2), 167-182. https://doi.org/10.1108/004009108108 62146

Isenberg, J. \& Jacob, E., 1983, 'Literacy and symbolic play: A review of the literature', Childhood Education 59(4), 272-276.

Janse van Rensburg, O., 2016, 'Creativity with young children', paper presented at the early childhood development STEM conference, Potchefstroom, South Africa, 10-12th October.

Jeanneret, N. \& DeGraffenreid, G.M., 2012, 'Music education in the generalis classroom', in G.E. McPherson \& G.E. Welch (eds.), The Oxford handbook of music education, pp. 399-16, Oxford University Press, Oxford.

Kara, H., 2015, Creative research methods in the social sciences, Policy Press, Bristol.

Krippendorff, K.H., 2013, Content analysis: An introduction to its methodology, Sage, Thousand oaks, CA.

Labuschagne, A., 2003, 'Qualitative research: Airy fairy or fundamental?', The Qualitative Report 8(1), Article 7, viewed 15 June 2017, from http://nsuworks. nova.edu/cgi/viewcontent.cgi?article=1901\&context=tqr

Laugksch, R.C., 2000, 'Scientific literacy: A conceptual overview', Science Education 84(1), 71-94.

Levinowitz, L.M., 1998, 'The importance of music in early childhood', General Music Today 12, 4-7.

Lind, K.K., 1999, 'Science in early childhood: Developing and acquiring fundamental concepts and skills', in D. Burts, C. Hart \& R. Charlesworth (eds.), Dialogue on early childhood science, mathematics, and technology education, pp. 73-83, AAAS, Washington, DC

Matacic, C., 2016, Rhythm might be hardwired in humans, viewed 17 July 2017, from http://www.sciencemag.org/news/2016/12/rhythm-might-be-hardwiredhumans

Merriam, S.B., 1988, Case study research in education: A qualitative approach, Jossey Bass, San Francisco, CA.

Merriam, S.B. \& Tisdell, E.J., 2016, Qualitative research, Jossey-Bass, San Francisco, CA.

Miller, J.D., 1983, 'Scientific literacy: A conceptual and empirical review', Scientific Literacy 112(2), 29-48.

Moyles, J., 1989, Just playing? The role and status of play in early childhood education, Open University Press, Maidenhead.

Novak, J.D., 1981, 'Applying learning psychology and philosophy of science to biology teaching', The American Biology Teacher 43(1), 12-20+42.

Patton, M.Q., 1990, Qualitative evaluation and research methods, 2nd edn., Sage, Newbury Park, CA.

Perkins, D., 1992, Smart schools: From training memories to educating minds, The Free Press, New York.

Phillips-Silver, J. \& Trainor, L.J., 2005, 'Feeling the beat: Movement influences infant rhythm perception', Science 308(5727), 1430. https://doi.org/10.1126/ science.1110922

Pickett, L., 1998, 'Literacy learning during block play', Journal of Research in Childhood Education 12(2), 225-230. https://doi.org/10.1080/02568549809594886

Raffini, J.P., 1993, Winners without losers: Structures and strategies for increasing student motivation to learn, Prentice Hall, Upper Saddle River, NJ.

Robinson, K., 2002, 'Teacher education for a new world of musics', in B. Reimer (ed.) World musics and music education: Facing the issues, pp. 219-238, National Association for Music Education, Reston, VA.
Rogers, G.L., 2016, 'The music of the spheres', Music Educator's Journal 103(1), 41-48. https://doi.org/10.1177/0027432116654547

Sharapan, H., 2012, 'From STEM to STEAM: How early childhood educators can apply Fred Rogers' approach', Young Children 67(1), 36-40.

Shively, J., 2015, 'Constructivism in music education', Arts Education Policy Review 116, 128-136. https://doi.org/10.1080/10632913.2015.1011815

Shortland, M., 1988, 'Advocating science: Literacy and public understanding', Impact of Science on Society 38(4), 305-316.

Simons, H., 2009, Case study research in practice, Sage, Thousand Oaks, CA.

South Africa, 2011, Curriculum and assessment policy statement foundation phase English life skills, Department of Basic Education, Pretoria.

Stewart, C., 2009, Preschool science: Learning at the playground!, viewed 17 July 2017, from https://www.education.com/magazine/article/preschool-scienceplayground/

Sylva, K., Roy, C. \& Painter, M., 1980, Child watching at playgroup and nursery school, Grant McIntyre, London.

Tunnicliffe, S.D., 2015, Starting inquiry-based science in the early years: Look, talk, think and do, Routledge, New York.

Van der Linde, C.H., 1999, 'The Relationship between Play and Music in Early Childhood: Educational Insights', Education 119(4), 610-615.

Van Vreden, M., 2014, Musiekintegrasie in graad $R$ : ' $n$ Teoretiese raamwerk gebaseer op 'n gevallestudie, PhD Proefskrif, NWU, Potchefstroom.

Van Vreden, M., 2016, 'Maestro for a moment: A conceptual framework for music integration in Grade R', South African Journal of Childhood Education 6(1), 1-10. https://doi.org/10.4102/sajce.v6i1.373

Volchegorskaya, E. \& Nogina, O., 2014, 'Musical development in early childhood', Procedia - Social and Behavioural Sciences 146(2014), 364-368. https://doi. org/10.1016/j.sbspro.2014.08.113

Vygotsky, L., 1966, Play and its role in the mental development of the child: Soviet psychological processes, Harvard University Press, Cambridge, MA.

Whitbread, D., Basilio, M., Kuvalja, M. \& Verma, M., 2012, The importance of play: A report on the value of children's play with a series of policy recommendations, Toys Industries for Europe, Brussels.

Wiggins, J., 2009, Teaching for musical understanding, Oakland University, Rochester, MI.

Wilson, R., 2007, Promoting the development of scientific thinking, Early Childhood NEWS, Excelligence Learning Corporation, viewed 15 June 2017, from http:// www.earlychildhoodnews.com/earlychildhood/article view.aspx? Articleld $=409 \% 20$

Windsor, L., 2013, 'Using concept mapping in community based participatory research: A mixed methods approach', Journal of Mixed Methods Research 7(3), 274-293. https://doi.org/10.1177/1558689813479175

Wolkowicz, T., 2017, 'Concept-based arts integration: Lessons learned from an application in music and biology', Music Educators Journal 103(4), 40-47. https:// doi.org/10.1177/0027432117697004

Yin, R.K., 2014, Case study research: Design and methods, 5th edn., Sage, Thousand Oaks, CA.

Zeece, P.D., 1999, 'Things of nature and the nature of things: Natural science-based literature for young children', Early Childhood Education Journal 26(3), 161-166. literature for young children', Early Childhood
https://doi.org/10.1023/A:1022929401934

Zentner, M. \& Eerola, T., 2010, 'Rhythmic engagement with music in infancy', Proceedings of the National Academy of Sciences 107(13), 5768-5773. https:// doi.org/10.1073/pnas.1000121107 